\title{
A Comparative Analysis of the Colour Subject between Canada Saskatchewan State and Visual Arts Education Curriculum in Turkey
}

\author{
Meral Per Dabancal 1 \\ Correspondence: Meral Per Dabancalı, Faculty of Education, Abant Izzet Baysal University, Turkey
}

Received: July 30, 2015 Accepted: August 18, $2015 \quad$ Online Published: August 31, 2015

doi:10.11114/jets.v3i6.991

URL: http://dx.doi.org/10.11114/jets.v3i6.991

\begin{abstract}
A deeper analysis of the art education curriculums applied in developed countries and treating specific subjects within these curriculums holds vital importance in allowing the production of alternative solution methods by providing the educators multiple perspectives in the face of problems concerning art education.

In present paper colour subject in Visual Arts Course curriculums applied in Canada Saskatchewan State and elementary \& secondary education schools in Turkey have been compared and contrasted. According to the findings of current research, acquisitions related to colour teaching are exemplified elaborately under goal of Creative/Productive art education in Saskatchewan whilst in Turkey the same acquisitions are listed under a wider scope termed as Visual Communication and Formation learning domain. It has been identified that in Saskatchewan elementary school, students are provided with the basics of colour knowledge and in secondary level, students are motivated to knowingly apply the basic theoretical information acquired in primary school in their original works. It has been detected that colour subject in Turkish elementary curriculum draws parallelism to a great extend with the elementary education curriculum in Saskatchewan while secondary school art education curriculum in Turkey provides acquisitions mostly in $9^{\text {th }}$ grade and in 10,11 and $12^{\text {th }}$ grades learnings acquired in $9^{\text {th }}$ class are applied to art works.
\end{abstract}

Keywords: Art education, Saskatchewan art education, Turkish art education, colour, colour teaching

\section{Introduction}

Comparative Education is among the sub-branches of educational sciences. Although Comparative Education can not be viewed as a domain attempting to find global solutions to worldwide educational problems, it is still a discipline leading each country to act in a wider perspective while attempting to find solutions to their national educational problems. In Turkey however Comparative Education is a field that still needs to be matured with higher quantities of literature studies. So as to meet the apparent need for more data in the field of Comparative Education in Turkey and find out solutions for the existing problems in education it would be logical to analyze the curriculums in a variety of developed countries (Erdoğan, 2006).

Visual arts education is a creative process in which, by means of the principles and orders of art, the individual can liberally express oneself and enhance his/her aesthetical value standards. According to Buyurgan and Buyurgan (2001), effectiveness of visual art education, which obviously contributes greatly to the positive development of one's personality, not only depends on creating adequate curriculums but also the ability of educators to reflect sufficient volume of knowledge and assets. A deeper analysis of the art education curriculums applied in developed countries and treating specific subjects within these curriculums hold vital importance in allowing the production of alternative solution methods by providing the educators multiple perspectives in the face of problems concerning art education.

Throughout history scientists and artists have aimed to develop colour theories. In any work of art, colour is seen as the unique language that expresses the image, effect and ways of operation of that artwork. In some cases colour alone can stand out as the only way of expression in the work. A correct knowledge on colour is a requisite for the implementer to formulate the colours that are reflected on canvas with different variations and to truly mirror his/her own attitude, opinions and experiences in the work of art. As a design component with the greatest number of subcategories, colour is heavily used by students while they put into practice their visual arts knowledge. Once students grasp knowledge on colour they will then be able to knowingly implement correct application materials and language of colours in their artworks and also they shall engage in the right terminology while conversing about art works. As long as the teacher presents components of art and principles of design within a context attracting students s/he can, upon grasping different 
colour schemes and techniques, develop an approach on the expression methods that can be acquired via colours. Additionally a refined sense of colour approach plays role in the life-long aesthetic standards of the individual. Therefore colour education, which is one of the design components of art, plays critical value in the visual arts education.

Bearing a vast geographical composition, Canada is a country officially divided into 10 states. Education is constitutional liability of each single state. Despite the presence of major differences in the curriculums of individual states overall educational level is in a high standard which largely explains the motives in selecting art education model in Canada for the purpose of our research. Data provided about Canada, Saskatchewan State hereby are reflective of the personal observations and analyses that the researcher singly conducted in this country for a length of 1 year.

In present research elementary and secondary art education curriculums in Saskatchewan State within the borders of West Canada region in Canada and elementary \& secondary art education curriculums in Turkey have been contrasted. Colour subjects listed in visual arts course in these curriculums have been examined. Accordingly, in the results part of present research, within the context of learning goal, learning outcomes, indicator and art activities in K-12 teaching curriculum, the sections that aim for colour teaching in each grade level have been examined and colour subject in secondary education visual arts lesson has also been detailed. However secondary education is shorter that the elementary since in K-12 curriculum colour teaching is mostly given in elementary level while in secondary level students are expected to transform the acquisitions in elementary education into original artworks after practicing, improving and bettering the theories. Likewise in the findings part of research learning domains of colour subjects in elementary \& secondary visual arts curriculum in Turkey and relevant acquisitions have been analyzed. As of 2012-2013 academic year, with the enforcement of 222 no Elementary School and Education Law, previously implemented 8-year continuous compulsory education in Turkey has been replaced with 4 years elementary school, 4 years secondary school, 4 years high school education which in sum corresponded to 12 years of compulsory progressive education model. Thereby present research is based on the new education curriculum in which Visual Arts Course is allocated 1 hour per week in elementary stage. Additionally in secondary education curriculum there is an Elective Visual Arts course aside from the required course. In present research colour subject in the contexts of 1 hour weekly required Visual Arts course as the joint course in Elementary \& Secondary school curriculums in Canada Saskatchewan State \& Turkey is examined. Colour subject can be treated under a number of learning outcomes in visual arts course. Nevertheless in present research learning objectives, learning outcomes and relevant indicators which are all directly linked to colour teaching have been analyzed. In this research learning outcomes, acquisitions and indicators may not follow a sequence since they are presented with the original numbers in their respective curriculums.

In the conclusion and discussion part of present research, in the light of obtained findings, colour subjects in elementary $\&$ secondary art education curriculums in Turkey and Canada Saskatchewan State have been contrasted to illustrate the similarities and divergences. Lastly suggestions, which can potentially improve visual arts education in Turkey, have been shared.

\section{Method}

The study is based on a comparative education research. In comparative researches there are different approaches that can be listed as vertical, horizontal, problem solution, case study, descriptive, explanatory and evaluative. In this research descriptive approach has been utilized. Descriptive approach consists of document collection, observation and comparing the facts via describing similarities and differences (Ültanır, 2000). In our study colour subject, which is one of the design components in the contexts of both curriculums, has been contrasted and the similarities and differences in between have been deciphered.

\section{Findings}

\subsection{Colour Subject in Canada Saskatchewan State Elementary Level Visual Arts Course Curriculums}

Elementary Education Art Curriculum in Canada Saskatchewan state is defined as K-12. Arts education is a Required Area of a Study in Saskatchewan's Core Curriculum. Elementary Art education is given from kindergarten to $5^{\text {th }}$ grade during a whole academic year 200 minutes per week. Distribution of total 200 hours of education is as listed below:

Dance.................... 50 minutes per week

Drama...................50 minutes per week

Music....................50 minutes per week

Visual Art.............50 minutes per week (SMoE, 2011a).

The K-12 aim of the arts education curriculum is to enable students to understand and value arts expressions throughout the life. From kindergarten till $12^{\text {th }}$ grade art education focuses on three main goals namely Cultural/Historical $(\mathrm{CH})$, 
Critical/Responsive (CR), Creative/Productive (CP) art. Under these general goals there are specific learning outcomes and indicators in each course (dance, drama, music, visual art) (SMoE, 2011a).

Cultural/Historical $(\mathrm{CH})$ : Students will investigate the content and aesthetics of the arts within cultural, historical, and contemporary contexts and understand the connection between the arts and the human experience.

Critical/Responsive (CR): Students will respond to artistic expressions of Saskatchewan, Canadian, and International artists using critical thinking, research, creativity, and collaborative inquiry.

Creative/Productive (CP): Students will inquire, create, and communicate through dance, drama, music and visual art (SMoE, 2011a).

Elementary education level posits eight institutional goals.

The students will:

1. Understand the elements of art and develop concepts that lead to an understanding of order in the visual environment.

2. Begin to develop skills that help them depict people and objects accurately.

3. Begin to understand the variety of sources for visual art ideas.

4. Begin to develop own ideas into visual art expressions, using the processes and materials of visual art.

5. Begin to think and talk about own visual art ideas and expressions.

6. Develop understanding of the work of a variety of visual artists.

7. Begin to talk about, interpret, and respond to works of art.

8. Become aware of the visual environment and visual art in the daily life of own community (SMoE, 2006).

The first goal (understand the elements of art and develop concepts that lead to an understanding of order in the visual environment) involves colour teaching. Below-given table illustrates the scope and sequence of learnings on colour subject which are related to the goal from kindergarten to $5^{\text {th }}$ grade. As the table manifests colour subject is heavily emphasized in the grade-specific objectives of this goal.

Table 1. Stages of Development from Kindergarten till $2^{\text {nd }}$ grade

\begin{tabular}{|c|c|c|}
\hline Kindergarten & Grade 1 & Grade 2 \\
\hline $\begin{array}{l}\text { Understand the elements of art anc } \\
\text { environment. }\end{array}$ & that lead to a & nderstanding of order in the visual \\
\hline \multirow[t]{2}{*}{$\begin{array}{l}\text { Know the meaning of the words } \\
\text { line, colour, texture, shape, form and } \\
\text { space } \\
\text { Identify colours in own surroundings } \\
\text { and in art works }\end{array}$} & $\begin{array}{l}\text { Know the meaning of the words } \\
\text { line, colour, texture, shape, form } \\
\text { and space } \\
\text { Identify many different colours in } \\
\text { own surroundings and in art works, } \\
\text { and identify red, yellow and blue as } \\
\text { primary colours }\end{array}$ & $\begin{array}{l}\text { Know that line, colour, texture, } \\
\text { shape, form and space are called the } \\
\text { elements of visual art } \\
\text { Understand that secondary colours } \\
\text { are created when you combine two } \\
\text { primary colours }\end{array}$ \\
\hline & & $\begin{array}{l}\text { Understand that the same colour can } \\
\text { be light and dark }\end{array}$ \\
\hline
\end{tabular}

(SMoE, 2006)

Table 2. Stages of Development from $3^{\text {rd }}$ till $5^{\text {th }}$ grade

\begin{tabular}{|c|c|c|}
\hline Grade 3 & Grade 4 & Grade 5 \\
\hline $\begin{array}{l}\text { Understand the elements of art a } \\
\text { environment. }\end{array}$ & epts that lead to a & he vi \\
\hline $\begin{array}{l}\text { Know that line, colour, texture, } \\
\text { shape, form and space are called the } \\
\text { elements of visual art }\end{array}$ & $\begin{array}{l}\text { Understand that line, colour, } \\
\text { texture, shape, form and space } \\
\text { comprise the basic language of } \\
\text { visual art }\end{array}$ & $\begin{array}{l}\text { Understand that line, colour, } \\
\text { texture, shape, form and space } \\
\text { comprise the basic language of } \\
\text { visual art }\end{array}$ \\
\hline $\begin{array}{l}\text { Know that the colour wheel is a way } \\
\text { of showing colour relations }\end{array}$ & $\begin{array}{l}\text { Recognize complementary colours } \\
\text { as being opposite each other on the } \\
\text { colour wheel }\end{array}$ & $\begin{array}{l}\text { Understand that pure colours have } \\
\text { hue, while neutral colours do not }\end{array}$ \\
\hline $\begin{array}{l}\text { Understand that adding white or } \\
\text { black changes the value of a colour }\end{array}$ & $\begin{array}{l}\text { Recognize analogous colours as } \\
\text { those that share a common hue }\end{array}$ & $\begin{array}{l}\text { Explore colour relationships in the } \\
\text { environment and in own } \\
\text { surroundings }\end{array}$ \\
\hline
\end{tabular}

(SMoE, 2006)

Towards the aim of obtaining meaningful contexts in Elementary level Visual Arts course a different conceptual focus has been defined for each grade. Each focus allows for purely disciplinary and/or interdisciplinary teaching and 
learning.

The focus for each grade is as follows:

- Patterns for Grade 1

- Community for Grade 2

- Environment for Grade 3

- Saskatchewan Voices for Grade 4

- Pop Culture for Grade 5 (SMoE, 2006).

In K-12 Art Teaching Curriculum colour subject has been defined within the context of art components as line, texture, shape, form and space. Also there are samples of warm-up activities in the units which may be utilized by teachers if need arises.

Colour subjects in K-12 curriculum have been analyzed per grade level below. In this analysis with respect to each grade level one of Cultural/Historical (CH), Critical/Responsive (CR), Creative/Productive (CP) K 12 goals, learning outcomes of this goal and indicators of learning outcomes have been listed. In $7^{\text {th }}$ grade no colour subject could be detected.

\subsubsection{Kindergarten}

K-12 Goal: Creative/Productive (CP)

Outcome: CPK.4 Create art works that express own observations and ideas about the world.

Indicator:

a. Identify different lines, colours, textures, shapes, forms, and patterns in surroundings and art works, and apply this understanding in own work.

K-12 Goal: Critical/Responsive (CR)

Outcome: CRK.1 Respond the arts expressions verbally and non-verbally (e.g., through movement or drawing).

Indicator:

f. Observe and respond to a range of arts expressions, incorporating age-appropriate discussion of arts elements and principles (eg., lines and colours in drawing book illustrations, rhythm or dynamics of a song, use a space in a dance, variety of roles in a drama) (SMoE, 2010).

\subsubsection{Grade 1}

\section{K-12 Goal: Creative/Productive (CP)}

Outcome: CP1.7 Investigate a variety of formal and informal patterns in art works and the environment, and apply observations to own work.

Indicator:

b. Represent details of the physical appearance of plants, animals, people, and objects, noting how patterns can be created by repetition of colours, lines, and shapes.

Outcome: CP1.8 Create art works that express own ideas and explore different forms (e.g., painting, drawing, printmaking) and media (paint, found objects).

Indicator:

a. Identify and explore many different colours in own surroundings and in art works, and identify red, yellow, and blue as primary colours.

K-12 Goal: Critical/Responsive (CR)

Outcome: CR1 Demonstrate understanding that the arts are a way of expressing ideas.

Indicator:

f. Use grade-appropriate arts terminology when discussing the arts (e.g., bright colours, quiet sounds, fast movements) (SMoE, 2011a).

\subsubsection{Grade 2}

K-12 Goal: Creative/Productive (CP)

Outcome: CP2.8 Create art works using a variety of visual art concepts (e.g., secondary colours), forms (e.g., collage, 
drawing, painting, sculpture, mobile, traditional art), and media (e.g., paper, found objects, paint, crayons).

Indicators:

d. Illustrate how secondary colours are created when combining two primary colours.

e. Investigate and illustrate how the same colour can be light or dark (SMoE, 2011b).

3.1.4 Grade 3

K-12 Goal: Creative/Productive (CP)

Outcome: CP3.8 Create art works using a variety of visual art concepts (e.g., contour lines), forms (e.g., drawing, sculpture) and media (e.g., pencils, pastels, found objects).

Indicators:

c. Investigate relationships of colours on the colour wheel.

d. Demonstrate ways to change a colour's value by adding white or black (SMoE, 2011c).

\subsubsection{Grade 4}

K-12 Goal: Creative/Productive (CP)

Outcome: CP4.8 Create art works using a variety of visual art concepts (e.g., organic shapes), forms (e.g., kinetic sculpture, mural), and media (e.g., wood, wire, and found objects).

Indicators:

a. Demonstrate imaginative use of the elements of art including line, colour, texture, shape, form, and space.

b. Recognize complementary colours as being opposite each other on the colour wheel.

c. Recognize analogous colours as those that share a common hue (SMoE, 2011d)

3.1.6 Grade 5

K-12 Goal: Creative/Productive (CP)

Outcome: CP5.8 Create art works using a variety of visual art concepts (e.g., positive space), forms (e.g., graphic design, photography), and media (e.g., mixed media, paint).

Indicators:

a. Use the elements of line, colour, texture, shape, form, and space in ways that reflect a pop art style.

b. Explore colour relationships in the environment and in pop art styles.

d. Examine ways of creating contrast (e.g., bold/subtle, rough/smooth, light/dark) (SMoE, 2011e).

3.1.7 Grade 6

K-12 Goal: Creative/Productive (CP)

Outcome: CP6.11 Investigate and use various visual art forms, images, and art-making processes to express ideas about identity.

Indicators:

b. Investigate how visual artists and popular media manipulate the elements of art (i.e., line, colour, texture, shape, form and space) and principles of design (e.g., balance, rhythm, emphasis, variety, contrast, proportion/scale) to achieve intentions, and apply understanding to own work.

e. Examine ways of creating contrast (e.g., bold/subtle, rough/smooth, light/dark) (SMoE, 2011f).

\subsubsection{Grade 8}

K-12 Goal: Creative/Productive (CP)

Outcome: CP8.11 Select and use appropriate forms, technologies, images, and art-making processes to express student perspectives on social issues.

Indicator:

d. Examine how visual weight is created through the use of size, colour, contour, contrast, texture, value, position, and so on (SMoE, 2011g).

3.1.9 Grade 9 


\section{K-12 Goal: Creative/Productive (CP)}

Outcome: CP9.12 Solve visual art problems in new and unfamiliar ways.

Indicator:

c. Solve visual art challenges or problems in innovative ways (e.g., imaginative use of point of view, perspective, colour theory, proportion, exaggeration, or distortion) (SMoE, 2011h).

\subsection{Colour Subject in Canada Saskatchewan State Secondary Level Visual Arts Course Curriculums}

In the Kindergarten to grade nine curriculum guides, the four strands are presented in separate sections. In the Arts Education 10, 20, 30 document all four strands are again presented separately, but they are interrelated within each module of the curriculum.

At the Secondary Level, the Arts Education curriculum incorporates the four strands of dance, drama, music and visual art within modules. The modular curriculum structure encourages teachers to plan their arts curriculums in series of connected lessons (SMoE, 1996).

All students will have taken the four strand Arts Education curriculum at the Elementary and Middle Levels. The Secondary Level is developed along a continuum of learning that began at the Elementary Level (SMoE, 1996).

\subsubsection{Visual Art Strand}

In visual art modules there are suggested activities, resources, foundational and learning objectives for the teachers. In the visual art strand students experience visual art as artists and as audience. The course for each grade should be based on a 100 hour course time allotment (SMoE, 1996).

The visual art strand provides students with opportunities to:

- Develop their perceptual abilities

- Learn to use the language, methods and materials of visual art

- Explore their own and other artists' ideas, experiences, feelings, cultural identities, observations and imaginations through visual art expressions

- Examine the role of visual art in cultures and societies, past and present, and explore the role of visual images in their own daily lives

- Examine critically and reflect upon art works of all kinds (SMoE, 1996).

\subsubsection{Explore the elements of art and principles of design within meaningful contexts}

The elements and principles are best explored in a context of interest to the students, rather than in isolation. Students should be encouraged to learn about the elements and principles as they encounter them in their visual art experiences. What the students discover about the elements and principles should be reinforced and applied throughout the year. Under the guidance of teachers it becomes feasible for students to reflect the colour knowledge they acquired during elementary education on their original works. Arts element and Principles, Element of Visual Arts (line, colour, texture, shape, form) are the frequently encountered headings in curriculum (SMoE, 1996).

Students at the secondary level should further their study of colour in the environment, learn about many colour relationships, and study the many relationships between colour and their daily lives. Through an exploration of different colour schemes and techniques, students should develop an understanding of some of the expressive qualities that can be achieved through colour. The teacher should continue to provide activities that require the students to explore a variety of media and tools and to use colours in a variety of ways. A colour wheel can be a good resource to help students understand and organize colours (SMoE, 1996).

Students at the Secondary Level should:

- Further the study of colour in the environment (natural and constructed) and study the effect different colours and colour combinations have upon the individual

- Analyze how visual artists have created and used colour to express different ideas and experiences (SMoE, 1996).

\subsection{Colour Subject in Turkish Elementary Level Visual Arts Course Curriculum}

Education curriculum in Turkey was prepared in line with General Objectives and Basic Principles of Turkish National Education stipulated under $2^{\text {nd }}$ Article in 1739 no Fundamental Law of National Education. As of 2012-2013 academic year, with the enforcement of 222 no Elementary School and Education Law, previously implemented 8-year continuous compulsory education in Turkey has been replaced with 4 years elementary school, 4 years secondary school, 4 years high school education which in sum corresponded to 12 years of compulsory progressive education model. In 
elementary level Visual Arts Course is a required 1 hour per week course. Additionally in secondary level curriculum there is an Elective Visual Arts course aside from the required course (MEB, 2013b).

Visual Arts Curriculum has focused on three basic learning domains that are identical in required and elective courses. These domains are:

- Visual Communication and Formation

- Cultural Legacy

- Art Criticism and Aesthetics (MEB, 2013b).

Acquisitions relevant of these three basic learning domains emphasized in curriculum must be interconnected in the lesson pacing. In the domain of Visual Communication \& Formation it is aimed to lead the students to utilize art components (colour, line, shape, form, texture, space/location) and design principles (rhythm, balance, ratio-proportion, focus, unity, variety, motion, contrast) in their visual art works (MEB, 2013b).

Below is given colour subjects in Turkish elementary education curriculum with respect to learning domains and acquisitions as per each grade level (MEB, 2013b).

\subsubsection{Kindergarten}

By taking into account developmental features of children in preschool education curriculum, acquisitions on motor development, cognitive development, language development, social and emotional development and self-care skills have been compiled (MEB, 2013a).

In preschool education curriculums teachers will register the months in which they treat the concepts identified under specific categories into the "Chart for treating the concepts in monthly educational plan". Colour stands out as the very first concept under such categories. The teacher registers here the analyzed colours and colour tones with respect to months (MEB, 2013a).

Learnings related to colour subject are placed within the category of Cognitive Development Acquisitions. Acquisitions and indicators for colour teaching are as provided hereinafter. Students will:

Acquisition 5: Observe the objects and things.

Indicator: Say the colour of the object/thing.

Acquisition 6: Match the objects or things according to their features.

Indicator: Differentiate/match the objects or things according to their colour.

Acquisition 7: Group the objects or things according to their features.

Indicator: Group the objects/things according to their colour.

Acquisition 8: Compare the features of objects or things.

Indicator: Differentiate, compare the colour of the object/things.

Acquisition 9: Order the objects or things according to their features.

Indicator: Order the objects/things according to their colour tones (MEB, 2013a).

\subsubsection{Grade 1}

Learning domain: Visual Communication and Formation

Acquisition: 1.1.10. Utilize art components and design principles while forming own visual artwork.

In this acquisition students learn primary colours.

Learning domain: Art Criticism and Aesthetics

Acquisition: 1.3.2. Say the formational features of the artistic work.

In this acquisition artwork is selected according to the age level of the student and analyzed with respect to colour, line, form/shape (MEB, 2013b).

\subsubsection{Grade 2}

Learning domain: Visual Communication and Formation

Acquisition: 2.1.1. Seek various solution methods for the problems encountered in the formation of visual artwork.

In this acquisition students are led to question how to express the specific topic, how to create the space, which colours, line, shape and form to apply. 
Acquisition: 2.1.10. Utilize art components and design principles while forming own visual art work.

In this acquisition students learn secondary colours (MEB, 2013b).

3.3.4 Grade 3

Learning domain: Visual Communication and Formation

Acquisition: 3.1.7. Utilize art components and design principles while forming own visual art work.

In this acquisition students are taught topics such as bright-dull colours, dark-light colours and complementary colours.

Learning domain: Art Criticism and Aesthetics

Acquisition: 3.3.4. Expresses own judgment on an analyzed art work.

In this acquisition, at the analysis phase, students are asked about the order of colours, the domination of bright or dull colours in the art work (MEB, 2013b).

\subsubsection{Grade 4}

Learning domain: Visual Communication and Formation

Acquisition: 4.1.8. Prepare three-dimensional models by utilizing dissimilar materials.

Also indicate in the work the colour and texture components specified under 4.1.9. no acquisition.

Acquisition: 4.1.9. Utilize art components and design principles while forming own visual art work.

In this acquisition, types of colour are taught as light, dark and intense colour. Also value concept, colour intensity, grading and shading are taught (MEB, 2013b).

\subsubsection{Grade 5}

Learning domain: Visual Communication and Formation

Acquisition: 5.1.7. Utilize art components and design principles while forming own visual art work.

In this acquisition students form light, dark and tone values of colour and also learn value concept, colour intensity, grading and shading (MEB, 2013b).

\subsubsection{Grade 6}

Learning domain: Visual Communication and Formation

Acquisition: 6.1.9. Utilize art components and design principles while forming own visual art work.

In this acquisition, students learn colour relations and value of colour (MEB, 2013b).

\subsubsection{Grade 7}

Learning domain: Visual Communication and Formation

Acquisition: 7.1.8. Utilize art components and design principles while forming own visual art work.

In this acquisition, students learn chromatic colour relations and chroma of a colour (transmission of a colour from brightness to dullness or from sparkling to grayness) (MEB, 2013b).

\subsubsection{Grade 8}

Learning domain: Visual Communication and Formation

Acquisition: 8.1.9. Utilize art components and design principles while forming own visual art work.

In this acquisition students learn complementary relations of colour (MEB, 2013b).

\subsection{Colour Subject in Turkish Secondary Level (Grade 9-12) Visual Arts Course Curriculum}

Secondary Education Visual Arts Course Curriculum has been structured over three learning domains as "Visual Art Culture", "Formation in Visual Arts", "Historical Environment and Museum Awareness". Student acquisitions and sample activities have been prepared accordingly, then presented. Among these learning domains Formation in Visual Arts domain is an area which integrates colour subject. Here colour subject is, in line with selected activities, the suggested methods and techniques, developed and practiced within the scope of activities directed towards affective and kinetic acquisitions. In Secondary Education, Visual Arts Course is a required 1 hour course per week (MEB, 2009).

\subsubsection{Grade 9}

Learning domain: Formation in Visual Arts

Sub-learning domain: Light-shade and light-dark 
Acquisitions:

2. Students explain via samples the effects of light-shade and light-medium-dark values on drawings.

4. Students create volume by utilizing light-medium-dark values that emerge with the light and shade in their drawings (MEB, 2009).

Sub-learning domain: Texture

Acquisitions:

6. Students express texture features of the objects and surfaces via colour (MEB, 2009).

Sub Learning domain: Perspective

Acquisitions:

4. Students provide artistic samples to demonstrate line and colour perspective.

9. Students utilize colour perspective in their drawings (MEB, 2009).

Sub Learning domain: Colour

With the below-listed acquisitions students can;

1. Explain with daily life samples the dissolution of white light into its colours.

2. Detect the effect of light in colour formation.

3. Recognize colour harmonies by using colour wheel.

4. Differentiate between colour harmonies and colour focus in artistic works.

5. Utilize colour harmonies and contrasts in visual art applications colour.

6. Utilize colours appropriate to his/her own daily life (MEB, 2009).

Sub Learning domain: Coloured Drawing Applications I

With the below-listed acquisitions students can;

1. Differentiate coloured drawing techniques.

2. Explain the features of materials used in coloured drawing techniques.

3. Practice coloured drawing techniques.

4. Explain drawing types per subject on coloured drawings.

5. Apply colour and spot values on the drawing.

6. State the effect of colour values in volume formation.

7. Benefit from artistic organization principles in coloured drawing applications (MEB, 2009).

3.4.2 Grade 10

Learning domain: Formation in Visual Arts

Sub Learning domain: Coloured Drawing Applications II

In this grade, student acquisitions are using coloured drawing techniques such as pastel, watercolour, gouache and collage in their original works and transferring $9^{\text {th }}$ grade colour sub-domain theoretical knowledge to their art works (MEB, 2009).

\subsubsection{Grade 11}

In this grade, students' artistic activities are associated with Coloured Drawing Applications I and II learning domains of grades 9 and 10 (MEB, 2009).

\subsubsection{Grade 12}

In this grade students' artistic activities are associated with colour sub learning domain in Formation of $9^{\text {th }}$ grade visual arts domain (MEB, 2009).

\section{Results}

The results obtained by comparing colour subject in elementary \& secondary art education curriculums in Canada Saskatchewan State and Turkey are as listed below:

- In both countries Visual Arts course is 1 hour per week. 
- In Canada Saskatchewan State secondary education starts at $10^{\text {th }}$ grade whilst in Turkey secondary education starts at $9^{\text {th }}$ grade.

- In education curriculums of Canada Saskatchewan State colour subject is given extensive place under Creative/Productive goal, which is one of the three goals of art education. In Turkey colour teaching takes up wider space under Visual Communication and Formation learning domain.

- In preschool art education curriculum of Canada Saskatchewan State children identify colours in their surroundings and art works and apply this understanding in their own work. Appropriate to their age they learn the art components and principles, or in other terms, the colours. In the preschool education curriculum in Turkey colour subject as a concept is listed under cognitive acquisitions. These acquisitions are not directed to colour knowledge about the colour activities in visual arts course but aimed to recognize the colours of objects and things in their surroundings.

- In both educational curriculums primary colours (red, blue and yellow) are taught in $1^{\text {st }}$ grade; secondary colours in (green, purple and orange) $2^{\text {nd }}$ grade. In Canada Saskatchewan State curriculum students also investigate light-dark values of the same colour while they are in $2^{\text {nd }}$ grade.

- In Turkish Visual Arts Education Curriculum bright-dull colours, dark-light and complementary colours are treated in $3^{\text {rd }}$ grade. In Canada Saskatchewan State curriculum however in $3^{\text {rd }}$ grade colour relations are examined on a colour wheel and the methods to change a colour value by adding white and black are presented to pupils.

- In Canada Saskatchewan State curriculum, in $4^{\text {th }}$ grade, demonstrate imaginative use of colours and complementary $\&$ analogous colour relations are presented on a colour wheel. In the $4^{\text {th }}$ grade in Turkey however aside from colour types light-dark colours and colour value concept are examined.

- In Canada Saskatchewan State curriculum, in $5^{\text {th }}$ grade, it is witnessed that colours and colour relations are examined in their surroundings and also pop art styles while in Turkey $5^{\text {th }}$ grade colour acquisitions are identical to the $4^{\text {th }}$ grade acquisitions.

- In Canada Saskatchewan State curriculum, in $6^{\text {th }}$ grade, students examine ways of creating contrast. In Turkey on the other hand $6^{\text {th }}$ graders learn about colour relations and colour value.

- In Canada Saskatchewan State curriculum, in $7^{\text {th }}$ grade, there is no acquisition on colour subject whereas in Turkey chromatic colour relations are explained in $7^{\text {th }}$ grade.

- In Canada Saskatchewan State curriculum, in $8^{\text {th }}$ grade, students examine how visual weight is created through the use of colour. In Turkey complementary relations of colours are explained in $8^{\text {th }}$ grade.

- In Canada Saskatchewan State curriculum, in $9^{\text {th }}$ grade, an acquisition is gained as regards solving the visual art problems via innovative ways such as colour theories. In Turkey's $9^{\text {th }}$ grade light-shade, expression of textures via colours, colour perspective and applying colour in drawing techniques are some of the treated topics. In Turkish secondary art education curriculum colour subject is mostly common during $9^{\text {th }}$ grade. In 10,11 and $12^{\text {th }}$ grades the theoretical knowledge gained in $9^{\text {th }}$ grade is put into practice.

- It is detected that in Saskatchewan state students acquire a developed perspective on the use of colour as early as elementary education. Thus in secondary education level $(10,20,30)$ they receive training towards knowledgeable use of colour in art works by communicating via a correct terminology on colours.

Based on the results obtained from present research, below-specified suggestions have been listed:

1. In Turkey a preschool art education curriculum should be formed and within this curriculum art education should be integrated as a specific teaching domain in preschool period. In that manner colour education can be started at an early age and aesthetic perspective of the child can be developed from the very onset.

2. In Canada Saskatchewan State curriculum, colour wheel is used starting from the 3 and $4^{\text {th }}$ grades. The term colour wheel which is an effective material in indicating colour relations should be integrated to art education curriculums to be a reference for Turkish elementary school teachers while analyzing colour relations in class.

3. It is witnessed that in Turkish elementary school art education curriculum acquisitions related to colour teaching are identical in the $4^{\text {th }}$ and $5^{\text {th }}$ grades. Thus it is possible to ensure that based on the age level of students further developed acquisitions could be given in $5^{\text {th }}$ grade.

4. In Turkey presence of a more developed acquisition on colour in $8^{\text {th }}$ grade level would be a preparation for a more intense colour knowledge in the $9^{\text {th }}$ grade. 


\section{References}

Buyurgan, S., \& Buyurgan, U. (2001). Sanat Ĕ̆itimi ve Öğretimi. Ankara: Dersal Yayıncılık Erdoğan, İ. (2006). Çağdaş Ĕ̆itim Sistemleri. İstanbul: Sistem Yayıncılık

Milli, E. B. (MEB). (2013b). İlkokul ve Ortaokul Görsel Sanatlar Dersi Öğretim Programı (1-8. Sınıflar). Ankara: Milli Eğitim Bakanlığ 1 Yayınları.

Milli, E. B. (MEB). (2014). Seçmeli Görsel Sanatlar Dersi Öğretim Programı Ortaokullar 5-8. Sınıflar. Ankara: Milli Eğitim Bakanlığı Yayınları.

Milli, E. B. (MEB). (2013a). Okul Öncesi Eğitimi Programı. Ankara: Milli Eğitim Bakanlığı Yayınları.

Milli, E. B. (MEB). (2009). Ortaöğretim 9, 10, 11, 12. Sinıflar Görsel Sanatlar (Resim) Dersi Öğretim Programı. Ankara: Milli Eğitim Bakanlığı Yayınları.

Saskatchewan Ministry of Education (SMoE). (1996). Arts Education 10, 20, 30. A Curriculum Guide for the Secondary Level. http://www.curriculum.gov.sk.ca/index.jsp?lang=en\&subj=arts_education\&level=102030

Saskatchewan Ministry of Education (SMoE). (2011a). Saskatchewan Curriculum Arts Education 1. https://www.edonline.sk.ca/bbcswebdav/library/curricula/English/Arts_education/Arts_Education_1_2011.pdf

Saskatchewan Ministry of Education (SMoE). (2011b). Saskatchewan Curriculum Arts Education 2. https://www.edonline.sk.ca/bbcswebdav/library/curricula/English/Arts_education/Arts_Education_2_2011.pdf

Saskatchewan Ministry of Education (SMoE). (2011c). Saskatchewan Curriculum Arts Education 3.

https://www.edonline.sk.ca/bbcswebdav/library/curricula/English/Arts_education/Arts_Education_3_2011.pdf

Saskatchewan Ministry of Education. (SMoE). (2011d). Saskatchewan Curriculum Arts Education 4. https://www.edonline.sk.ca/bbcswebdav/library/curricula/English/Arts_education/Arts_Education_4_2011.pdf

Saskatchewan Ministry of Education (SMoE). (2011e). Saskatchewan Curriculum Arts Education 5. https://www.edonline.sk.ca/bbcswebdav/library/curricula/English/Arts_education/Arts_Education_5_2011.pdf

Saskatchewan Ministry of Education (SMoE). (2011f). Saskatchewan Curriculum Arts Education 6. http://www.curriculum.gov.sk.ca/index.jsp?lang=en\&subj=arts_education\&level=6

Saskatchewan Ministry of Education (SMoE). (2011g). Saskatchewan Curriculum Arts Education 8. http://www.curriculum.gov.sk.ca/index.jsp?lang=en\&subj=arts_education\&level=8

Saskatchewan Ministry of Education (SMoE). (2011h). Saskatchewan Curriculum Arts Education 9. http://www.curriculum.gov.sk.ca/index.jsp?lang=en\&subj=arts_education\&level=9

Saskatchewan Ministry of Education (SMoE). (2010). Saskatchewan Curriculum Kindergarten. https://www.edonline.sk.ca/bbcswebdav/library/curricula/English/Master_K_Curr_2010_Final.pdf

Saskatchewan Ministry of Education (SMoE). (2006). Arts Education: A Curriculum Guide for the Elementary Level (K-1). SK, Canada.

Saskatchewan Ministry of Education (SMoE). (1996). Visual Art 10, 20, 30 Curriculum Requirements. SK, Canada.

Ültanır, G. (2000). Karşılaştırmalı Eğitim Bilimi. Ankara: Eylül Kitap ve Yayınevi.

\section{$(\mathrm{Cc}) \mathrm{BY}$}

This work is licensed under a Creative Commons Attribution 3.0 License. 